\title{
When Leaders Matter: Rebel Experience and Nuclear Proliferation
}

\author{
Matthew Fuhrmann \\ Michael C. Horowitz \\ Texas A\&M University \\ mfuhrmann@tamu. edu \\ University of Pennsylvania \\ horom@sas . upenn. edu
}

October 21, 2013 


\begin{abstract}
This paper contributes to a growing literature on leaders in international politics by explaining why and how the background experiences of leaders influence nuclear proliferation. Given nuclear weapons' crucial role in world politics, examining the importance of leaders for nuclear proliferation represents a key development in research on leaders. We argue that leaders with a particular experience - participation in a rebellion against the state - are more likely than their non-rebel counterparts to pursue nuclear weapons. Former rebels are aware of the contingency of their rule and more likely to value weapons that could bolster national independence. Drawing on a new dataset on leader participation in rebel activities, we analyze 1,322 leaders in office from 1945 to 2000. The results strongly support our theory, even when accounting for leader selection. Our findings underscore the value in using leaders - not just states - as a unit of analysis in international relations research.
\end{abstract}


The United States maintained a strict containment regime against Iraq in the 1990s and then invaded the country in 2003, in part, because of concerns about the spread of weapons of mass destruction (WMD). A critical assumption underlying American policy was that there was a link between the leader of the country, Saddam Hussein, and Iraq's pursuit of WMD - particularly nuclear weapons. Many in Washington believed that Saddam was the driving force behind Iraq's purported nuclear weapons program and that Iraq would no longer covet the bomb if he could be removed from power. President Bill Clinton expressed this viewpoint when he plainly said in February 1998, "Do I think [Iraq] would be better served if it had a different leader? Of course I do" (Gellman \& Walsh 1998).

The case of Iraq - despite all of its controversies and complexities - underscores that the beliefs and experiences of individual leaders matter for international politics, particularly when it comes to understanding the pursuit of military technologies that can improve national security such as nuclear weapons. Yet standard political science explanations for how and why nuclear weapons spread downplay or ignore the role of leaders. The classic realist argument, for example, suggests that states pursue nuclear weapons when they face external security threats (e.g., Waltz 1990; Paul 2000). Leaders are irrelevant, according to this line of thinking, because individuals will make similar choices when presented with the same structural conditions. Other prominent theories including those that emphasize international institutions and norms (e.g., Dai 2002; Rublee 2009), alliances (e.g., Frankel 1993), or knowledge and technology diffusion (e.g., Fuhrmann 2012) - likewise assume that leaders have little effect on nuclear proliferation dynamics. Even arguments centering on domestic politics largely overlook the beliefs and backgrounds of leaders, focusing instead on a state's political institutions (e.g., Singh \& Way 2004; Jo \& Gartzke 2007; Way \& Weeks 2012).

In this article, we theorize that leaders with a particular type of background experience - namely, participation in a rebellion against the state - are significantly more likely to pursue nuclear weapons once in office than other types of leaders. Former rebels place a special emphasis on ensuring national independence and discount the utility of external alliances to provide for their security, making the pursuit of advanced military technologies more likely. Such leaders also tend to underestimate the financial and political costs of building the bomb, creating the perception that nuclear weapons programs are likely to succeed. 
We test our argument using a sample of 1,322 leaders from 1945 to 2000 that is constructed with existing data on nuclear proliferation and a new dataset on leader participation in rebel activities. The results reveal a strong and significant correlation between leaders with prior rebel backgrounds and the pursuit of nuclear weapons. Prior rebels are 542 percent more likely than non-rebels to pursue nuclear weapons, all other things being equal. One potential concern is that this relationship reflects an endogenous selection process whereby the countries that are most likely to produce leaders with prior rebel experience are also systematically more likely to pursue nuclear weapons. Yet, our analysis controls for this possibility by accounting for irregular entry into office, civil war, regime type, and other variables that might enable rebels to come to power. Moreover, our main finding holds when we use country fixed effects, matching analysis, and a series of other robustness tests designed to isolate the background experiences of leaders from various countryrelated circumstances. Although establishing causation using observational data can be challenging, this evidence strongly favors our theory that there is a non-spurious relationship between rebel experience and nuclear proliferation.

Our analysis speaks to two enduring debates in political science. First, since the publication of Kenneth Waltz's Man, the State, and War (1959), scholars in international relations have discussed which level of analysis - the individual, the state, or the system - allows us to best understand political phenomena. The overwhelming majority of research focuses on the state or the system, but we contribute to ongoing efforts to develop leader-centric explanations by showing how the background experiences of individuals affect a critical national security issue. Second, understanding the factors that motivate states to build nuclear weapons has been a central issue in international relations since their debut in 1945. Scholarly interest in nuclear proliferation is surging in light of the ongoing crises in Iran and North Korea, as evidenced by the sheer number of recent books and articles on the subject. At the same time, we still lack a complete understanding of how and why nuclear weapons spread. We offer a novel theory of nuclear proliferation that sheds new light on this important issue.

We proceed by explaining why a focus on leaders can enhance our understanding of proliferation dynamics. Next, we introduce our theory about how rebel experience affects leaders' propensities to pursue nuclear weapons. We then describe the new data we utilize to test this argument and present 
the statistical results, showing that our findings hold whether one uses simple bivariate comparisons or multivariate regression analysis. In the penultimate section, we discuss potential objections, and our conclusion follows.

\section{Leaders and Nuclear Weapons: Does a Link Exist?}

The study of leaders in international relations has grown significantly over the last several years. While some research places more causal weight on the way that institutions influence leaders, rather than the other way around (e.g., Debs \& Goemans 2010; Chiozza \& Goemans 2011; Croco 2011), an increasing number of scholars have shown that leaders themselves play a vital role in determining national policy. Life experiences prior to when a leader assumes office constitute a testing bed for leaders when they later consider the strategies that are most likely to succeed (Jervis 1976). Prior life experiences influence everything from how leaders evaluate the costs and benefits of particular actions to whether they consider particular options in the first place (Goldgeier 1994; Sechser 2004; Roberts et al. 2003; Matthews 1954). Recent research shows that revolutionary leaders shape national behavior (Colgan 2010, 2013), that leaders influence the intervention strategies countries pursue (Saunders 2011), and that the efficacy beliefs of leaders drive their decisions (Kennedy 2011). Building on this small but growing literature, we argue that leaders' background experiences affect nuclear proliferation. Why might this be the case?

When deciding whether to build nuclear weapons, countries must grapple with a multitude of potential costs and benefits. Many scholars believe that nuclear weapons provide political and strategic benefits to their possessors (e.g., Waltz 1990; Beardsley \& Asal 2009; Narang 2009). Most notably, nuclear weapons constitute a form of "invasion insurance." States with the ability to retaliate in a violent conflict by using the bomb are seen as less vulnerable to invasion. Yet, on the down side, nuclear weapons programs are exorbitantly expensive and they can result in diplomatic isolation and economic sanctions, especially if the proliferator is party to the nuclear Nonproliferation Treaty (NPT) (e.g., Singh \& Way 2004; Jo \& Gartzke 2007). States that pursue the bomb may also face preventive military strikes against their nuclear facilities, as the cases of Iraq in 1981 and Syria in 2007 illustrate (Reiter 2006). 
Compounding matters further, building an independent nuclear arsenal is not the only way for a country to enhance its security. Many states instead rely on security guarantees from a nucleararmed ally. Because nuclear alliances serve as a substitute for developing an indigenous nuclear arsenal, states that are protected by a "nuclear umbrella" may have less of a need to build their own nuclear bombs (Frankel 1993). For example, the extension of the American nuclear umbrella over Japan dissuaded it from the pursuit of nuclear weapons (Sagan 1996). A critical decision point comes when a country has to decide whether it can provide for its own security without a nuclear weapons program, and especially without a nuclear-armed ally, or whether it should pursue the nuclear option.

Given the stakes associated with pursuing nuclear weapons, national leaders play a critical role in decisions about nuclear proliferation. ${ }^{1}$ Nuclear-related research and development sometimes occurs without direct political authorization. Members of the Indian Atomic Energy Commission, for instance, decided to construct a small nuclear reactor in 1969 without obtaining permission from Prime Minister Indira Gandhi (Perkovich 1999, 150). However, the actual decision to build the bomb is generally made at the highest levels of government (Hymans 2006, 10-11). No country, as far as we are aware, has launched a concerted and sustained effort to build nuclear weapons without the backing of a national leader. It is hard to say much about the Chinese bomb without mentioning Mao Zedong; Zulfikar Ali Bhutto was the clear driver of the Pakistani nuclear weapons program in the early stages, having famously proclaimed that his people would "eat grass" in order to build the bomb; Muammar Qaddafi was intimately associated with Libya's campaign to acquire WMD; there may not have been an Israeli nuclear weapons program in the 1950s without David Ben Gurion; and Josep Broz Tito was the face of Yugoslavia's early efforts to acquire atomic weapons.

Despite the seemingly obvious connection between leaders and nuclear proliferation, most research in political science has assumed that who is in power in a country has little bearing on the proliferation process. Yet there is some recognition that leaders play an important role. Solingen (2007), for example, suggests that leaders evaluate how decisions about nuclear proliferation will

\footnotetext{
${ }^{1}$ This is true even in democracies (where domestic politics often constrain leaders) because nuclear weapons programs are among the most secretive and discretionary of programs (Rhodes 1986).
} 
affect their ability to remain in power. She argues that ruling coalitions that favor integration in the global economy should be less likely to proliferate, while inward looking governments may exploit the bomb as a nationalist tool aimed at shoring up their hold on power. Hymans (2006) places even more emphasis on individual leaders, arguing that their conceptions of national identity affect whether they will build the bomb. In particular, leaders who have an "oppositional nationalist" national identity conception, which is characterized by the emotions of fear and pride, are more likely to go nuclear. O'Reilly (2012) similarly shows that a leader's perception of the international environment influences whether she decides to pursue the bomb. This research contributes to the proliferation literature by spotlighting attention on domestic institutions and leaders. However, scholarly understanding of how leaders' beliefs and experiences affect nuclear proliferation remains incomplete. Political scientists have yet to systematically consider how leaders' backgrounds - which shape their beliefs and worldviews - influence the spread of nuclear weapons. ${ }^{2}$

In the next section, we generate a new leader-centric theory of nuclear proliferation. Our theory turns the emphasis to the individual leader and, in particular, the way that leaders' prior life experiences may influence their propensity to seek nuclear weapons.

\section{Why Prior Rebel Experience Affects Nuclear Proliferation}

The experiences leaders have prior to entering office naturally shape the way they view the world. Life experiences shape everything from the way leaders view the likely success and failure of particular strategies to how they view their own personal efficacy at pursuing different policy options. Prior research shows that this can have a significant impact on the policies that leaders pursue in office (Saunders 2011; Jervis 1976; Goldgeier 1994; Kennedy 2011). We argue in this section that prior rebel service is a particularly poignant experience that causes leaders to excessively value national independence, distrust other countries to provide for their defense, and generally have a

\footnotetext{
${ }^{2}$ Existing research that focuses on leaders and proliferation is based on a small number of welldone historical case studies. Hymans, for instance, conducts an impressive historical analysis but his conclusions are based on only Argentina, Australia, France, and India. This article is the first to employ large-n analysis to the study of nuclear proliferation using leaders as the unit of analysis.
} 
higher tolerance for risk. Through these mechanisms, prior rebel participation makes leaders more likely to value the potential benefits of possessing nuclear weapons.

Rebel service represents an important life event, in part, because participants at the level of future leaders face the risk of death to advocate for a cause in which they believe. It often, though not always, occurs during in a period of life, early adulthood, where experiences have a largescale effect on future behavior (Roberts et al. 2003). Park Chung Hee, who led the "May 16 Revolution" in South Korea before becoming president of the country, underscored the salience of rebel service when he discussed the "weighty pressure" he felt after risking his life to lead the military coup (Park 1970, 21, 58). Although rebel service shares some similarities with uniformed military service, our argument about the focus on independence should be particular to former rebels. ${ }^{3}$ Prior participation in a rebellion increases the likelihood that leaders will try and build the bomb for two main reasons.

First, leaders that participate in rebellions before taking office - whether or not the rebellion itself is what brings them into power - have an appreciation of the tenuous nature of national authority and sovereignty. They have already existed in a world where they lacked power and influence over the organs of national power. Since prior rebel leaders have personal experience engaging in a military struggle for national independence or control of the government, they should place an especially high premium on independence and sovereignty. They have had to fight for their own independence, so they do not want to see it jeopardized. They are also more aware of how easily regime change can occur. While we tend to think about "who" constitutes rebels fairly narrowly, with leaders such as Mao coming to mind, anyone that attempts to overthrow the government is technically a rebel. ${ }^{4}$ Leaders with prior rebel experience are thus more likely to pursue policies designed to preserve independence. Park $(1970,155)$, for example, wrote in his memoir that "the Korean society should become independent ... and produce ... a self-ruling country" that is not overly reliant on the United States. That mindset is typical of a former rebel that comes to power.

\footnotetext{
${ }^{3}$ We also show in the online Appendix that including a variable for whether a leader served in a uniformed military does not change our results. They also do not change if we create a variable combining rebel and military experience.

${ }^{4}$ See the research design section for more on our rebel definition.
} 
Given that nuclear weapons can provide a critical degree of protection against invasion, it naturally makes former rebels positively inclined to think about building them. Indeed, rebel experience may cause leaders to embrace the identity characteristic of "oppositional nationalism" that Hymans $(2006,2)$ argues makes individuals more likely to support nuclear weapons programs. ${ }^{5}$ For example, Mao Zedong's worldview was profoundly influenced by his early experiences as a rebel and the tactics that allowed the Communists to succeed in the Chinese Civil War (Goldstein 2005; Schwartz 1951; Rice 1972). In particular, once in office, Mao's decision to build nuclear weapons was driven by nationalism and a desire to avoid being held hostage by the great powers (Kennedy 2011, 119-122). He feared that China and other non-nuclear states would be forced to "kneel and obey orders meekly, as if they were nuclear slaves" (Krepon 2009, 101). To avoid this outcome and pursue an independent foreign policy, Mao believed that China must possess nuclear weapons. He told colleagues in 1958 that without the bomb, "others don't think what we say carries weight" (Lewis \& Litai 1988, 36). In light of these views, which stemmed from Mao's revolutionary experiences, Beijing would probably have pursued nuclear weapons even without the crises in Korea, Indochina, and the Taiwan Strait (Lewis \& Litai 1988, 35).

The focus on independence and recognition of the tenuous nature of their rule also makes former rebels less willing to trust external security guarantees. Mao's persistent fear of great power interference and influence over China typifies this perspective (Kennedy 2011, 124-125). Former rebels are less likely to completely rely on alliances or extended deterrence promises to guarantee their security because their direct experience demonstrates the instability of those promises. For example, while Charles de Gaulle feared the Soviet Union more than the United States, he always worried about the extent to which allying with Washington would threaten France's independence (Spirtas 1998, 310). ${ }^{6}$ As Bozo (2001, xi) writes, "independence was the immutable bedrock of Gaullist policy within the alliance." When de Gaulle withdrew France from the military command of the North Atlantic Treaty Organization (NATO), the specific logic had to do with protecting

\footnotetext{
${ }^{5}$ In other words, prior rebel experience could represent one of the micro-foundations of oppositional nationalism.

${ }^{6}$ We discuss the de Gaulle coding below. Excluding de Gaulle or all French leaders does not significantly change the results reported below.
} 
France's independence and ensuring French sovereignty. De Gaulle rose to office specifically based on his promise to uphold French sovereignty and protect France given its recent experience of occupation during World War II (Grosser 1963, 200). This same reasoning drove the leaders of the Fourth Republic and de Gaulle to pursue nuclear weapons.

Rejecting military integration with NATO and arguing that France needed its own atomic bomb, de Gaulle explicitly argued that France had to provide for its own security, stating in a speech that "The nation's defense can only be a national defense" (Aron 1966, 159). Furniss (1961, 354) describes de Gaulle as thinking that "the weapon in French hands would be the indispensable requisite for national independence, and would enable France to take action alone if necessary to protect her vital interests." Former rebels who enter office are those that survive - and more often those that experience at least some degree of success in their rebellions. These life experiences gives leaders calculated reasons for not trusting external security guarantees and desiring security independence.

When leaders lack rebel experience, they are often more willing to trust their allies to provide for their security. For example, Japanese leaders since the 1950s - all of whom lacked rebel experience - generally trusted the United States to defend it and therefore perceived less of a strategic need for an independent nuclear deterrent. Leaders in Turkey and West Germany have likewise been dissuaded from going nuclear due, in part, to the NATO alliance.

A second reason to expect that former rebels will pursue nuclear weapons has to do with their greater risk acceptance. There is a reciprocal relationship between rebel experience and risk acceptance. On one hand, former rebels who become national leaders tend to be more risk acceptant as a whole. They are generally not the lower-level fighters that are coercively selected into a rebel group or otherwise join due to fears for personal safety (Kalyvas \& Kocher 2007). Instead, the decision to participate in a rebellion is a conscious choice made by individuals who are naturally willing to accept a higher level of risk, given the dangers. This is relevant because, as explained previously, pursuing nuclear weapons is also an exceptionally dangerous path. Nuclear weapons pursuit can invite external sanctions and force countries to bear significant economic costs. Countries can also place themselves at risk of attack in the interim before they acquire nuclear weapons or even once they have a small arsenal. Leaders who were willing to accept the dangers associated with rebel service should naturally be less worried about the hazards of pursuing nuclear weapons. 
On the other hand, rebel service itself can affect an individual's propensity to accept risk. Former rebels who become national leaders often believe that their actions will lead to success even when others view them as risky. Kennedy (2011), for example, shows how prior successes and failures shape the strategies that leaders consider in office and the extent to which they are willing to accept risks - or view choices as risky in the first place. For example, Mao's military successes as a rebel made him confident in his ability to use military coercion and threats to achieve his goals once he entered office, even when outside observers viewed those choices as risky. He had seen what he could accomplish when he focused China's people on an important objective (Rice 1972, 101). For Mao, those choices were not risky since they were similar to choices he had made in the past - and which had succeeded.

Since former rebels are more risk acceptant in general - or less likely to see actions as risky, as per Kennedy - they are likely to overestimate their ability to build nuclear weapons and underestimate the financial and international reputational costs of pursuing the bomb. Thus, efficacy beliefs drawn from their rebel experiences, combined with a greater predisposition to risk, could make former rebels even more likely to seek nuclear weapons. ${ }^{7}$ This general argument should also apply more broadly to policy choices that may be characterized as "risky." Indeed, recent research (Anonymous) demonstrates that former rebels are more likely to initiate militarized disputes and wars.

Our central claim is not that those with prior rebel experience will necessarily pursue nuclear weapons. There are many other factors that influence whether or not a leader decides to initiate or continue a nuclear weapons program. However, the theoretical argument advanced above suggests

${ }^{7}$ Jeff Colgan $(2010,2013)$ similarly argues that revolutionary leaders are more likely to initiate military conflicts because they are risk acceptant and ambitious. Our argument differs from Colgan's in two primary ways. First, Colgan's argument focuses mostly on how revolutionary regimes select for risk-acceptant leaders. While a part of our claim, our argument also emphasizes the efficacy beliefs derived from actual experience as a rebel. Second, our argument highlights how rebel experience cultivates an obsession with national independence, and this is not a mechanism emphaiszed by Colgan. Empirically, there is only a 37 percent overlap between Colgan's revolutionary leader variable and our rebel universe. We address the relationship between revolutionary leaders and rebels empirically in the online Appendix. 
that those with prior rebel experience should be more likely, all other things being equal, to pursue nuclear weapons. These leads to our central hypothesis:

Hypothesis 1. Countries with former rebels as heads of state are more likely than states with non-rebel leaders, on average, to pursue nuclear weapons programs.

\section{Potential Objections to the Argument}

One possibility is that our theory reflects an endogenous selection process whereby the countries that are most likely to produce leaders with prior rebel experience are also systematically more likely to pursue nuclear weapons. These types of leaders also might be especially insecure for institutional reasons (Chiozza \& Goemans 2011), making them more likely to engage in military buildups to prevent external invasion.

A relationship between rebel experience and nuclear proliferation might also merely indicate that countries emerging from civil wars or occupations are more likely to select leaders who share a preoccupation with national independence. Related to this, some countries - particularly those that recently experience civil wars - have a larger pool of rebel leaders from which the selectorate can choose. This omitted variable bias could influence any findings. Finally, our argument may simply reflect differences driven by regime types like personalist regimes.

We explicitly control for all of these possibilities in our empirical analysis below by accounting for the selection of rebels into office along with other potentially unexplained national level variance; doing so does not undermine our results. Leaders with prior rebel service have an important effect on the proliferation process even when we account for a variety of factors related to the security environment and institutional forces that bring leaders into office.

\section{Measuring Nuclear Proliferation and Rebel Experience}

Are former rebels more likely to pursue nuclear weapons? Answering this question requires data on nuclear weapons proliferation and participation in rebel activities.

Coding a state's nuclear behavior is sometimes challenging since nuclear weapons programs may be shrouded in secrecy. However, over the last decade, scholars have produced new time-series-cross- 
section datasets that identify states' interest in the bomb. We begin with a nuclear proliferation dataset compiled by Bleek (2010), which builds on earlier efforts to code nuclear behavior (e.g., Singh \& Way 2004; Jo \& Gartzke 2007). We use the Bleek data in part because it makes it harder to find evidence in favor of our theory. ${ }^{8}$ Almost all of the countries that were excluded by Bleek but that could plausibly be coded as pursuing nuclear weapons were ruled by former rebels: Argentina (Videla and Galtieri), Egypt (Nasser and Sadat), Syria (Al-Assad), and Taiwan (Chiang Kai-shek). We can therefore be more confident that our argument is correct if it is empirically supported using the Bleek dataset. As we show in the online Appendix to this article, including the aforementioned cases - and using other datasets employed in the literature - only strengthens the empirical support for our theory.

We adapted the existing data to make it suitable for a leader-centric analysis. Nuclear weapons programs often begin (and end) during years where there is at least one leadership turnover. India, for instance, first pursued nuclear weapons in 1964 - a year in which three different men were in power: Jawaharlal Nehru, Gulzarilal Nanda, and Lal Bahadur Shastri. The datasets used in other quantitative studies of nuclear proliferation do not tell us whether some or all of these leaders pursued the bomb. We therefore conducted additional historical research to determine which leaders initiated (and terminated) nuclear weapons programs. Returning to the Indian example, Shastri was the initiator of the nuclear explosives program, and his two immediate predecessors did not pursue the bomb.

A dichotomous variable, Nuclear weapons pursuit, is coded 1 if a leader is actively trying to build nuclear weapons in year $t$ and 0 if not. We show later in the paper, however, that our findings are consistent when we model the initiation of a nuclear weapons program only, excluding decisions to continue an existing program. ${ }^{9}$ Table 1 lists the leaders that pursued the bomb and years of pursuit. As the table reveals, 41 leaders in 16 different countries pursued nuclear weapons from

${ }^{8}$ Bleek also provides detailed case descriptions based on a large number of high quality sources, making it possible for us to scrutinize his coding decisions, though others have done that as well.

${ }^{9}$ This variable is coded missing once a state builds the bomb, meaning that nuclear weapons states are dropped from our sample. The online Appendix shows that including these states does not affect the results. 
1945 to 2000. Nuclear weapons pursuit occurs in about 3.1 percent $(214 / 6,735)$ of the leader-year observations in our sample.

We operationalize rebel experience using a new dataset that builds on the backbone of Archigos (Goemans et al. 2009) to incorporate the backgrounds of more than 2,500 leaders (Anonymous). This dataset includes a variable that categorizes leaders based on prior rebel service. Rebel experience is a dichotomous variable that is coded 1 if a leader participated in activities designed to overthrow the government of a state prior to coming into office and 0 otherwise. ${ }^{10}$ It is also important to note that our rebel variable includes individuals who participate in civil conflict (e.g., Mao) and wars of national liberation (e.g., de Gaulle). We utilize a fairly broad coding scheme because, theoretically, it is the act of rebelling and the fundamental risk associated with doing so that drives our argument. All of these types of rebellious activities involve being willing to overthrow a national government, making them rebel activity according to our theory.

One potential concern is that some rebels come into power immediately as a direct result of successful coups or revolutions (e.g., Zia) while others serve in office, often as a result of elections, years after participating in rebellious activities (e.g., several of the post-World War II French leaders). We account for both of these concerns in our models below by including an Irregular entry variable. This variable allows us to evaluate whether the relationship between rebel experience and nuclear proliferation is driven by leaders who enter office through irregular means such as coups.

Another possible objection to our rebel definition is that it includes leaders such as de Gaulle who were pursuing wars of national independence and wearing formal "uniforms," which could make them more like regular military personnel and less like rebels. ${ }^{11}$ De Gaulle had "rebelled against the state" (Thompson 1974, 257), but he did wear a "regular" military uniform. According to the

\footnotetext{
${ }^{10}$ Our definition captures violent (Castro) and nonviolent (Nehru) activities, as long as a participant's objective is to depose the leader in power. Reclassifying nonviolent leaders as non-rebels does not change the results. It might be fruitful to disaggregate participation in political violence - for example by distinguishing terrorism from participation in an armed rebellion. Unfortunately we do not have the data to explore this possibility, but it is a promising avenue for future research.

${ }^{11}$ We address this concern empirically below, showing that our results are consistent when we exclude many of the leaders who fought against external occupiers.
} 


\begin{tabular}{|c|c|c|}
\hline Country & Leader & Years \\
\hline \multirow{4}{*}{ Brazil } & Ernesto Geisel ${ }^{\star}$ & $1975-79$ \\
\hline & João Figueiredo & $1979-85$ \\
\hline & José Sarney & $1985-90$ \\
\hline & Fernando Collor de Mello & 1990 \\
\hline China & Mao Zedong ${ }^{\star}$ & $1956-63$ \\
\hline \multirow[t]{7}{*}{ France } & Pierre Mendes ${ }^{\star}$ & $1954-55$ \\
\hline & Edgar Faure ${ }^{\star}$ & $1955-56$ \\
\hline & Guy Mollet* & $1956-57$ \\
\hline & Maurice Bourges-Maunory ${ }^{\star}$ & 1957 \\
\hline & Felix Gaillard ${ }^{\star}$ & $1957-58$ \\
\hline & Pierre Pflimin ${ }^{\star}$ & 1958 \\
\hline & Charles de Gaulle & $1958-59$ \\
\hline \multirow[t]{4}{*}{ India } & Lal Bahadur Shastri* & $1964-66$ \\
\hline & Gulzari Lal Nanda* & 1966 \\
\hline & Indira Gandhi & $1966,1972-84$ \\
\hline & Rajiv Gandhi & $1984-86$ \\
\hline \multirow[t]{2}{*}{ Iran } & Akbar Hashemi Rafsanjani ${ }^{\star}$ & $1989-97$ \\
\hline & Mohammad Khatami & $1997-2000$ \\
\hline \multirow[t]{2}{*}{ Iraq } & Ahmed Hassan Al-Bakr* & 1976-79 \\
\hline & Saddam Hussein ${ }^{\star}$ & 1979-91 \\
\hline \multirow[t]{2}{*}{ Israel } & David Ben Gurion* & $1955-63$ \\
\hline & Levi Eshkol ${ }^{\star}$ & $1963-66$ \\
\hline Libya & Muammar Qaddafi* & $1970-2000$ \\
\hline \multirow{2}{*}{ North Korea } & Kim Il-Sung* & 1980-1994 \\
\hline & Kim Jong-Il & $1994-2000$ \\
\hline \multirow[t]{2}{*}{ Pakistan } & Zulfikar Ali Bhutto & $1972-77$ \\
\hline & Muhammad Zia* & $1977-86$ \\
\hline Russia & Josef Stalin ${ }^{\star}$ & $1945-48$ \\
\hline \multirow[t]{2}{*}{ South Africa } & John Vorster ${ }^{\star}$ & 1974-78 \\
\hline & P.W. Botha & 1978 \\
\hline South Korea & Park Chung-hee* & $1970-75$ \\
\hline \multirow[t]{7}{*}{ Yugoslavia } & Josip Broz Tito* & $1953-62$ \\
\hline & Petar Stambolic* & $1982-83$ \\
\hline & Mika Spiljak & $1983-84$ \\
\hline & Veselin Djuranovic ${ }^{\star}$ & $1984-85$ \\
\hline & Radovan Vlajkovic ${ }^{\star}$ & $1985-86$ \\
\hline & Sinan Hasani* & $1986-87$ \\
\hline & Lazar Mojsov^ & 1987 \\
\hline \multirow[t]{2}{*}{ United Kingdom } & Winston Churchill & 1945,1951 \\
\hline & Clement Atlee & $1945-51$ \\
\hline United States & Franklin D. Roosevelt & 1945 \\
\hline
\end{tabular}

NOTE: Data are right-censored; asterisks denote leaders with rebel experience

Table 1. Leaders and Nuclear Weapons Pursuit, 1945-2000. 
same rules used to classify those that fought against colonial occupations, de Gaulle's activities count as "rebel" action. It is not possible to gather extensive enough data on uniforming and other norms of behavior that might indicate experiences more like "regular" militaries. The clearest, most objective definition of rebel behavior is the definition we employ. However, we discuss the potential implications of this coding decision below when conducting our empirical analysis.

It is also important to note that leaders with rebel experience are not necessarily dictators. Some former rebels certainly became authoritarian leaders (e.g., Saddam and Stalin), but many others headed democratic governments (e.g., Ben Gurion and Aquino). Our rebel measure is therefore not simply a proxy for authoritarianism.

About 36 percent of the leader-year observations in our sample feature rebel experience. As Table 1 shows, many leaders who pursued nuclear weapons were former rebels. To properly evaluate whether this is indicative of a broader trend, we must compare the rate of nuclear proliferation among rebel leaders to non-rebels' propensity to build the bomb.

\section{Methods and Findings}

To test our hypothesis on the effect of leader experience on nuclear proliferation, we focus on leaders in the international system from 1945 to $2000 .{ }^{12}$ We obtained information on the universe of leaders as well as when they entered and exited office from Goemans et al. (2009). Our setup takes advantage of a larger amount of variation in national behavior than past studies by focusing on the leader-year rather than the country-year. Past research, even when it emphasizes the domestic political institutions of states, generally only has one observation per year even if there is more than one leader. This potentially introduces bias into the results, since each leader has to make a decision in a given year about whether or not to pursue nuclear weapons. To correct this, our unit of analysis is the leader year and we weigh each observation based on how long the leader spent in

\footnotetext{
${ }^{12}$ We begin our analysis in 1945 because data on many of our independent variables are unavailable prior to that date. We find support for our hypothesis when we extend the analysis back to 1940 and only include the covariates for which we have complete data.
} 


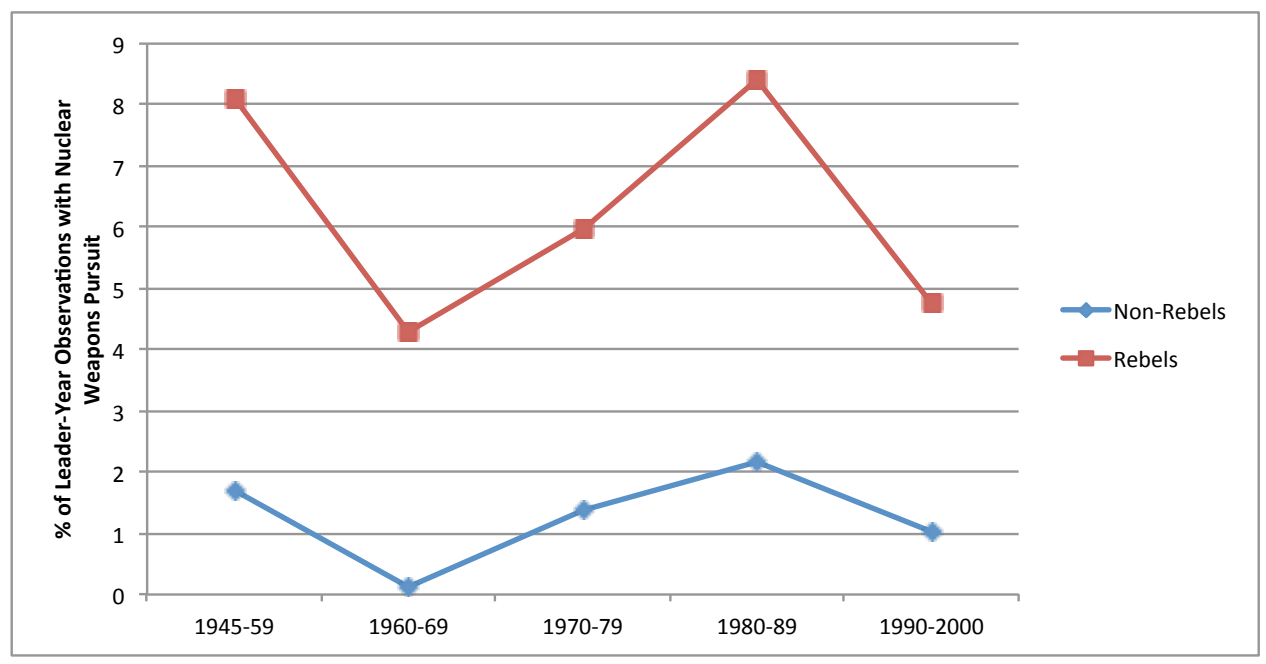

Figure 1. Rebel Experience and the Pursuit of Nuclear Weapons.

office that year. Our sample includes 1,322 leaders and a total of 6,949 leader-year observations. ${ }^{13}$

As a preliminary means of evaluating our hypothesis, we compare the rate of nuclear weapons pursuit among rebel and non-rebel observations in our sample. As Figure 1 illustrates, leaders with rebel experience are considerably more likely than leaders that lack this experience to pursue nuclear weapons. The percentage of leader-year observations featuring both nuclear weapons pursuit and rebel experience naturally fluctuates slightly over time, but the disparity between the behavior of rebels and non-rebels is striking across the entire nuclear age. During the 1980s, for instance, 8.42 percent of the leader-year observations in the sample with rebel experience experienced nuclear weapons pursuit - compared to only 2.15 percent for non-rebels.

These findings provide initial evidence in favor of our hypothesis. Yet every leader with rebel experience does not attempt to build nuclear weapons, and some leaders without rebel experience pursue the bomb. Remarkably, however, the overwhelming majority of leaders who were in power when nuclear weapons programs began were former rebels, as Table 1 above shows. Every country that pursued nuclear weapons - except the United Kingdom and the United States - had at least one former rebel in power while the government was actively trying to acquire the bomb.

The analysis conducted up to this point, however, does not account for other factors that could

\footnotetext{
${ }^{13}$ The number of observations in our sample fluctuates slightly based on which independent variables we include in our statistical model and how we construct the dependent variable.
} 
affect nuclear proliferation. Because rebel leaders are not randomly assigned to countries, we must account for confounding variables to be sure that the relationship between rebel experience and nuclear weapons is not spurious. We do so by conducting a multivariate statistical analysis that accounts for other explanations that are prominent in the existing literature on the causes of nuclear proliferation. When specifying our empirical models, we adopt a research strategy similar to the one employed by Way \& Weeks (2012). We are mindful of two potential issues: omitted variable bias and post-treatment bias. Omitted variable bias occurs when analysts exclude factors that are associated with the main independent variable of interest and the dependent variable. One could not properly evaluate the connection between party identification and voting, for instance, without controlling for race - a factor that influences one's choice of party and how she votes. Post-treatment bias results when scholars include covariates in their models that are caused by the key independent variable. As King \& Zeng $(2006,147)$ explain, including such variables inappropriately controls for the effects of the main variable, biasing the findings. In a study of how party identification affects voting behavior, it would be problematic to control for one's intended vote five minutes before entering the voting booth. Doing so would make it seem as though one's party does not affect how she votes, which of course is not the case (King \& Zeng 2006, 147).

In an ideal world, a proper test of the relationship between rebel experience and nuclear proliferation would control for factors that cause both of these variables, while excluding covariates that are caused by rebel experience. Despite our efforts to exclude variables that are obviously posttreatment, some might argue that a few of the controls described below could be a consequence of rebel experience. ${ }^{14}$ This is why the statistical analysis below begins with a "pure" model that only evaluates the effect of prior rebel experience on nuclear weapons pursuit. We also estimate a "trimmed" model that includes some control variables while excluding potentially problematic covariates and a "full" model that includes all of the controls. Our full model includes the following variables:

\footnotetext{
${ }^{14}$ However, some seemingly post-treatment controls are less problematic for our purposes. We argue that former rebels are less likely to trust alliances - not less likely to form them - so it is appropriate to control for alliances with nuclear-armed states. Former rebels may form alliances as insurance even if they end up having little effect on nuclear policy, as the case of France illustrates.
} 
Irregular entry, Civil war, and Polity. The countries that are most likely to produce leaders with prior rebel experience may also be systematically more likely to pursue nuclear weapons, as we previously discussed. We control for how a leader entered office, whether a country recently experienced civil war, and the nature of a state's domestic political institutions to account for this possibility. Irregular entry is a dichotomous variable that is coded 1 if a leader rose to power through irregular means and 0 if not (Goemans et al. 2009). A cross-tabulation of rebels and those who enter office through irregular means, available in the online Appendix, demonstrates that we have significant variation on how leaders enter office. ${ }^{15}$ Civil war is coded 1 if a country has been involved in a civil war in the last five years and 0 otherwise (Gleditsch et al. 2002). Polity measures a state's regime type based on the widely employed 21-point composite indicator (Marshall et al. 2009). ${ }^{16}$

Borders. Many have argued that states pursue nuclear weapons when they face external threats. Existing quantitative studies usually test this argument using standard indicators of a state's security environment such as participation in militarized interstate disputes. However, given that former rebels are more likely than non-rebels to initiate militarized disputes (Anonymous), interstate conflict is a "post-treatment" control and including it in our model could complicate our ability to unpack the relationship between rebel experience and nuclear weapons programs. Following Way \& Weeks (2012), we deal with this issue by using the number of land and sea borders as a proxy for a state's security environment. States that are geographically proximate to other countries are more likely to experience interstate conflict, but it would be hard to argue that leader backgrounds cause a state to have a greater (or fewer) number of neighbors. As we show below, however, our findings are similar when we use more traditional indicators of a state's security environment.

Superpower alliance. Alliances with nuclear-armed states can serve as a substitute for independent nuclear deterrents. We include a variable measuring whether a state has a defense pact with a superpower that possesses nuclear weapons.

\footnotetext{
${ }^{15}$ This measure is correlates with Rebel experience, but not at a level that would raise collinearityrelated concerns.

${ }^{16}$ This variable ranges from -10 to +10 , with higher scores indicating greater levels of democracy. As shown in the online Appendix, our findings are similar if we use dichotomous variables to operationalize democratic and autocratic regimes.
} 
Nuclear cooperation agreements. Foreign assistance in developing civilian nuclear programs is thought to increase the likelihood that a state will pursue nuclear weapons, in part, because it reduces the expected costs of a bomb program (Fuhrmann 2012). We control for the size of a state's civilian nuclear program by including a variable that counts the number of bilateral civilian nuclear cooperation agreements a state has signed from 1945 to year $t$ that entitle it to receive aid in developing nuclear energy for peaceful purposes.

Gross domestic product per capita. Wealthier states have a greater capacity to build nuclear weapons, which could make them more likely to pursue the bomb. We use a state's GDP per capita as a proxy for its wealth. ${ }^{17}$

Economic openness. States that are exposed to the global economy may be deterred from pursuing nuclear weapons by the prospect of economic sanctions or the loss of foreign investment (Solingen 2007). Consistent with a standard practice in the quantitative literature, we control for this by including the ratio of a state's trade (imports + exports) to its GDP.

Nonproliferation Treaty status. The NPT prohibits most states from building nuclear weapons. Because states generally want to keep the international commitments that they make, those that ratify the NPT may be less likely to pursue nuclear weapons than those that do not. For our purposes, it is not relevant whether one thinks of treaty ratification as a reflection of state interests or as a constraint on behavior. We construct a dichotomous variable coded 1 if a state has ratified the NPT in a given year and 0 otherwise. ${ }^{18}$ In the online Appendix, we show that our results are consistent even if we restrict the sample to the NPT time period, meaning they are not just driven by the pre-NPT period.

Time, Time ${ }^{2}$, and Time ${ }^{3}$. Most leaders are included in our dataset multiple times, and these within-leader observations may not be truly independent. To address possible temporal dependence in our data, we include a count of the number of years that have passed since a leader has been in power without pursuing nuclear weapons, along with its square and its cube (Carter \& Signorino 2010).

\footnotetext{
${ }^{17}$ We take the natural log of this measure to address the variable's skewed distribution.

${ }^{18}$ Given the "stickiness" of NPT ratification, we also estimate a model that measures the number of years a state has been party to the treaty and it does not affect the results.
} 
Table 2 displays the findings from a logit analysis of nuclear weapons pursuit. ${ }^{19}$ The standard errors are clustered by leader to address heteroskedasticity among heads of government in the sample. ${ }^{20}$ States often have multiple leaders in the same year because new leaders rarely begin their terms on January 1. As described above, we therefore weight each observation in the sample based on how many days a leader served in a year.

The four models in Table 2 test our hypothesis while addressing concerns about post-treatment bias. Our model generally makes good predictions about leaders' nuclear behavior, especially relative to what is typical in international relations research when using a panel dataset. A receiver operating characteristic (ROC) curve, available in the online Appendix, shows that the area under the curve is 0.97 , meaning that if a "proliferator" and a "nonproliferator" were drawn at random there is a 97 percent probability that the former would have a higher expected likelihood of proliferation.

One might take the extreme position that all of the control variables described above, in one way or another, could be caused by having a former rebel in power. We therefore begin with a model that includes Rebel experience along with the time-related variables and excludes the other controls (model 1). Next, we add the controls designed to account for the factors that might allow former rebels to come to power (Irregular entry, Civil war, and Polity) and Borders - the independent variable that controls for the security environment and is least likely to be caused by rebel experience (model 2). Model 3 is our full model that includes all of the covariates described earlier. Model 4 uses two alternate measures of a state's security in lieu of Borders: the five-year moving average of militarized interstate dispute participation (Militarized interstate disputes) and whether a state is involved in an enduring rivalry (Rivalry) (Singh \& Way 2004). As described above, these variables are post-treatment since research shows that former rebels are more likely to engage in militarized disputes (Anonymous), but they are included as covariates in most past proliferation research.

\footnotetext{
${ }^{19}$ Logit is an appropriate estimator because our dependent variable is dichotomous. We also estimate a rare events logit model and Cox regression analysis. The findings are similar in both cases (see the online Appendix).

${ }^{20}$ As shown in the online Appendix, the findings are similar when we cluster the standard errors by country.
} 


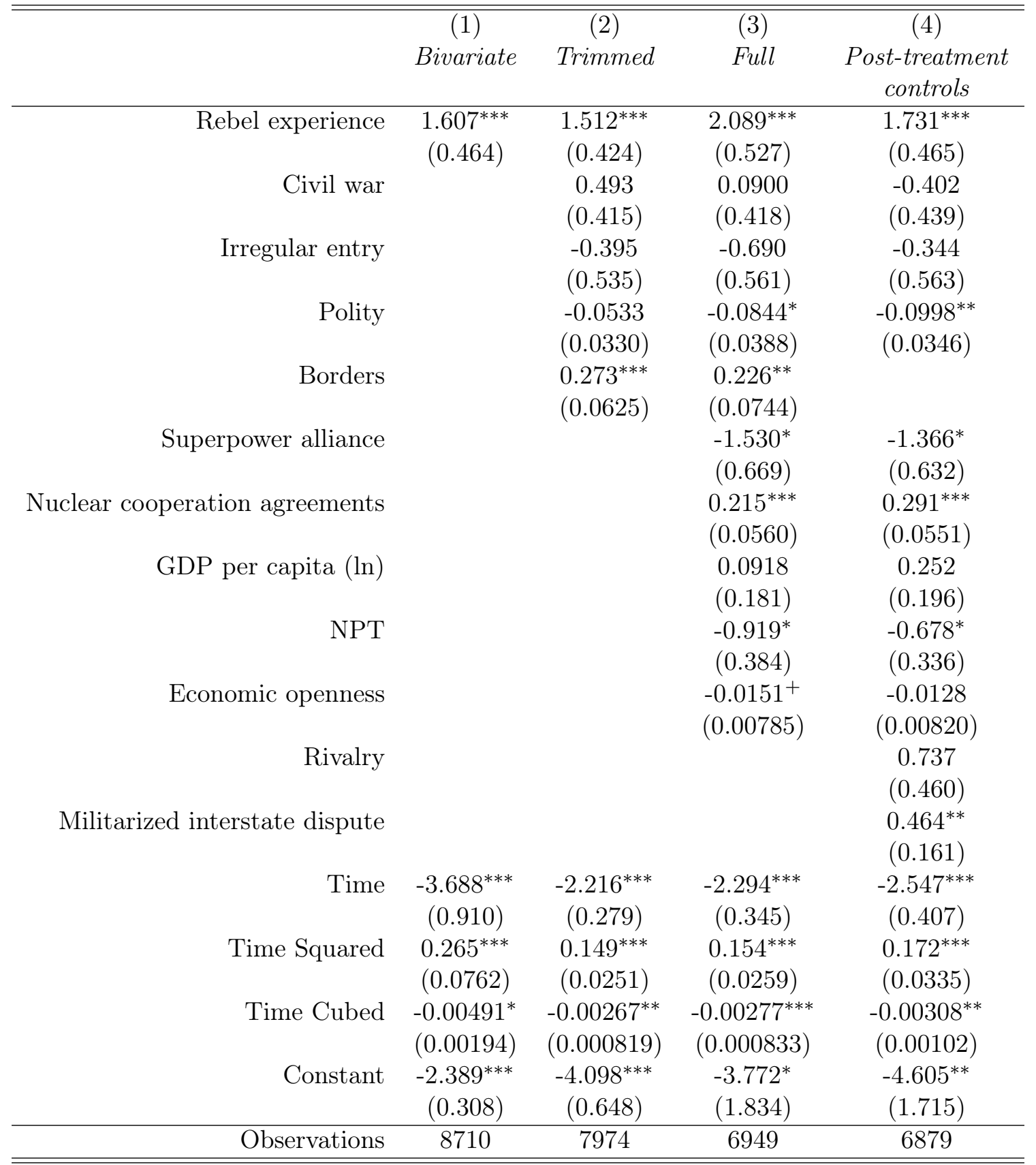

Standard errors in parentheses

${ }^{+} p<0.10,{ }^{*} p<0.05,{ }^{* *} p<.01,{ }^{* * *} p<.001$, two-tailed tests

Table 2. Logit analysis of nuclear weapons pursuit. 
The coefficient on Rebel experience is positive and statistically significant at conventional levels in all of the models from Table 2. In support of our theory, these findings reveal that there is less than a 0.1 percent chance that we would observe a relationship between rebel experience and nuclear proliferation by chance alone. The consistency of the results across models 1-4 demonstrates that our main finding is robust to various model specifications.

Specifically, as we mentioned previously, one potential concern is that these results simply reflect an endogenous selection process whereby the countries that are most likely to produce leaders with prior rebel experience - those that recently experienced civil wars or other domestic turmoil - are also systematically more likely to pursue nuclear weapons. We therefore control for whether a country was previously involved in a civil war, whether the leader entered office through irregular means such as a coup, and regime type to isolate the relative effect of former rebels. If countries that have recently experienced domestic turmoil are more likely to produce former rebels as leaders and more likely to pursue nuclear weapons, adding these variables should wash out the significance of Rebel experience. As models 2-4 show, however, adding these variables does not undermine our findings. Rebel experience remains strongly and significantly associated with the pursuit of nuclear weapons even when controlling for factors that might predict whether or not leaders have rebel experience.

The case of Israel usefully illuminates these results. Israeli Prime Minister David Ben-Gurion's prior rebel experience precipitated concerns about national independence that, in turn, contributed to his decision to build nuclear weapons. Ben-Gurion's experience fighting for Israeli independence led him to conclude that Israel could not rely on external powers to guarantee the existence of Israel (Cohen 1998, xxii, 12). According to Avner Cohen, this directly influenced Ben-Gurion's belief that Israel could only ensure its independence through acquiring nuclear weapons: "Ben-Gurion settled on the bomb as Israel's ultimate guarantee for survival in a hostile environment" (Cohen 1998, xxii). The Israeli leader's prior experience as a rebel and his perception of the insecurity of Jewish independence drove his threat perceptions in ways that made him less amenable to seeking out or trusting security guarantees from external powers.

The decisions of Belarus, Kazakhstan, and Ukraine regarding the nuclear weapons they inherited from the Soviet Union likewise provide supporting evidence in favor of our theory. Each country 
was newly independent and in the shadow of a great power that had colonized them - Russia. Yet each country decided to give up the nuclear weapons they inherited from the Soviet Union, making them more theoretically vulnerable to Russian coercion. While many factors drove their decision, it is notable that none of the three initial leaders of these states, Kravchuk (Belarus), Shushkevich (Ukraine), and Nazarbaev (Kazakhstan) had prior rebel experience. If these leaders had been former rebels, our theory predicts that they would have been more inclined to keep the inherited weapons.

How substantively important is rebel experience in shaping the probability of nuclear weapons pursuit? Figure 2 address this issue by displaying how the likelihood of nuclear proliferation changes when Rebel experience shifts from 0 to 1 and other factors are held constant at the sample means (for continuous variables) or modes (for dichotomous variables). ${ }^{21}$ The figure shows that former rebels have nearly a 25 percent probability of pursuing the bomb in a given year. Yet, under identical circumstances, non-rebels have a predicted probability of nuclear weapons pursuit of only about 4 percent. The confidence intervals around the predicted probabilities in these two scenarios do not overlap, meaning that the difference between them is statistically significant. To underscore the magnitude of this difference, we calculate the relative risk of Rebel experience - the ratio of the probability of nuclear weapons pursuit in the "treatment" group (leaders with rebel experience) divided by the same probability in the "control" group (leaders without rebel experience). The relative risk is 6.42 , meaning that rebel experience increases the probability of nuclear weapons pursuit by about 542 percent. As we discuss later, this is quite a large effect in comparison to the other variables in the model.

To further evaluate the relative impact of former rebel experience on proliferation, we isolate the effect of a country switching from a non-rebel leader to a rebel leader on the probability of initiating a nuclear weapons program. We generate a lag variable (Rebel lag) that equals 1 if the prior leader was a rebel and 0 otherwise, and interact it with the Rebel experience variable. The results, available in the online Appendix, demonstrate that switching from a non-rebel to a rebel leader dramatically increases the probability of nuclear weapons program initiation by over 17 times,

${ }^{21}$ These calculations are based on Model 3. The three time-related variables are held constant at 0. This will naturally increase the probability of proliferation with and without rebel experience compared to a scenario where the time-related variables are set to their mean values. 


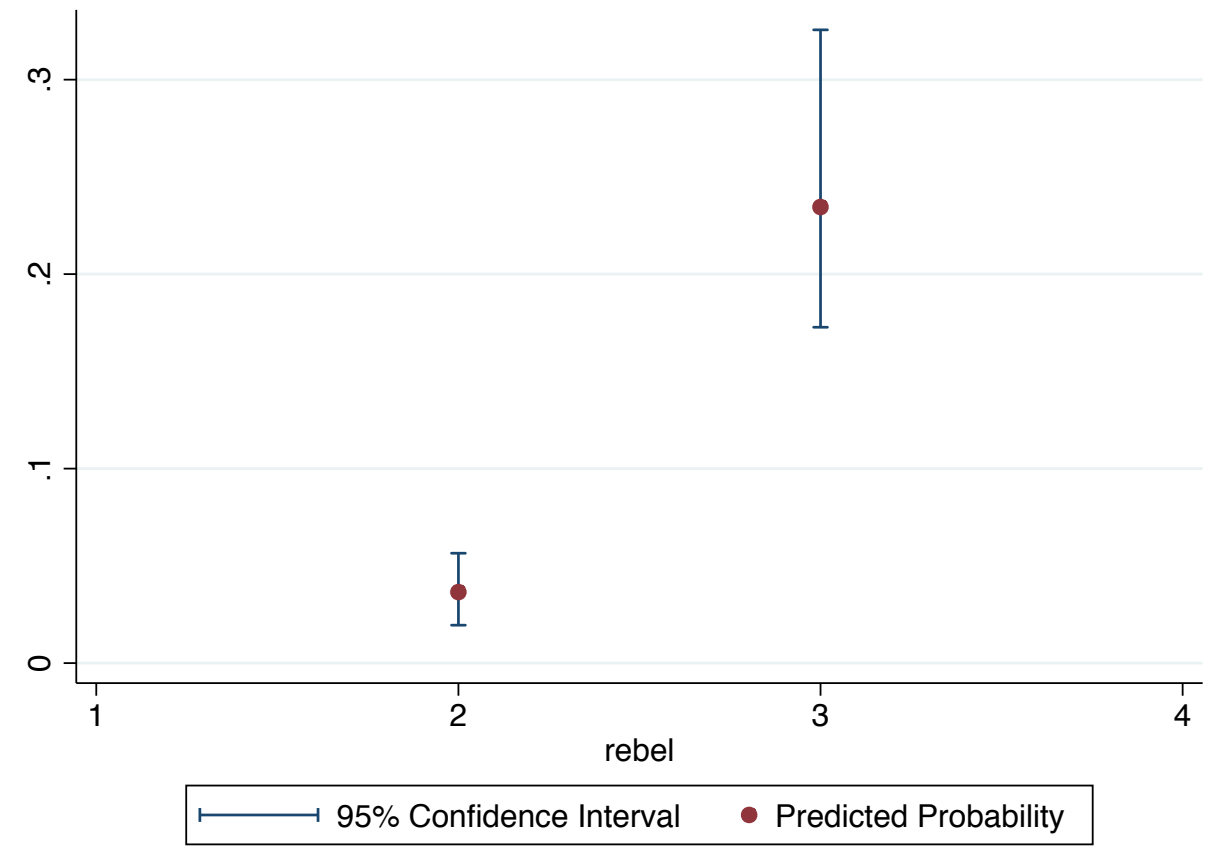

Figure 2. Predicted Probability of Nuclear Weapons Pursuit by Rebel Experience.

or over 1,600 percent, compared to switching from a non-rebel to another non-rebel leader.

Consider a case from the dataset - West Germany in 1974 - to illuminate the substantive importance of rebel experience. Many policymakers in the United States and the Soviet Union were concerned, with good reason, that West Germany would initiate a nuclear weapons program during the 1970s but Bonn ultimately remained nonnuclear. In 1974, West Germany elected a new leader, Helmut Schmidt, who lacked rebel experience. What if a leader who had participated in a militarized rebellion had instead rose to power? Our model predicts that the probability of a West Germany bomb program would have risen dramatically, from 0.28 to 0.76 , if a former rebel had been in power and all other factors remained constant. This does not imply that a different leader with rebel experience definitely would have pursued the bomb. There were other factors - including the alliance with the United States - that contributed to Bonn's nuclear restraint. However, the point here is that, according to our model, the probability of a West German nuclear weapons program would have increased dramatically if a leader with rebel experience had come to power in lieu of Schmidt.

In terms of the control variables, once we slightly relax our concern about post-treatment bias, 
our findings are similar to those reported in other studies. Threatening security environments appear to be associated with a higher likelihood of nuclear proliferation, as indicated by the positive and statistically significant coefficients on Borders (models 1-3) as well as Rivalry and Militarized interstate disputes (model 4). The coefficient on Nuclear cooperation agreements is positive and statistically significant, indicating that increases in nuclear assistance raise the likelihood of nuclear weapons pursuit. We also find that democracies, allies of superpowers, NPT members, and states that are exposed to the global economy are less likely to pursue the bomb. ${ }^{22}$ However, Irregular entry, Civil war, GDP per capita, and Economic openness are statistically insignificant. The results are also consistent when we add in the overall material capabilities of a state into the model (see the online Appendix). ${ }^{23}$

Some of the controls are substantively significant. For example, a one standard deviation increase in the number of nuclear cooperation agreements a state has signed (from 2 to 6 treaties) increases the probability of nuclear weapons pursuit by 124 percent. Generally speaking, however, the size of these effects is dwarfed by Rebel experience. These results indicate that our theory is not the only one that sheds light on nuclear proliferation, but rebel experience does appear to be among the most important factors that shape leaders' nuclear behavior. Figure A in the online Appendix compares the substantive effects of the control variables to the previously reported effect of Rebel experience.

The three time-related variables are statistically significant, and they collectively indicate that leaders are less likely to initiate a bomb program the longer that they serve in office without proliferating. Thus, if rebels are going to initiate a nuclear weapons program, they are likely to do so early in their tenure. Numerous cases underscore this point: Mendes, Rafsanjani, and Stambolic all initiated nuclear weapons programs the same year that they came to power; Geisel and Qaddafi

\footnotetext{
${ }^{22}$ The results are consistent if we change the alliance variable to reflect alliances with any nuclear powers, not just the superpowers. Consistent with our theory, alliances appear to deter non-rebel leaders from pursuing nuclear weapons, but the same is not true of rebels. The relevant findings are available in the online Appendix.

${ }^{23}$ We exclude this from the main models since it overlaps with our economic variables, and since it is post-treatment to prior rebel experience.
} 
launched bomb programs the year after taking control of government. We observe this effect, in part, because leaders transform their sources of power over time (Geddes 2008; Svolik 2007). Because institutions matter more the longer that rebels serve in office, the effect of prior rebel experience is strongest earlier in a leader's tenure.

In sum, regardless of how we specify the empirical model, we find a strong relationship between leader participation in rebellions and nuclear proliferation. Our analysis suggests that this relationship emerges because leaders are influenced by their prior experiences. Individuals - and not necessarily the factors that allow particular leaders to rise to power - therefore play an important role in the proliferation process even if leaders' backgrounds matter less the longer that they serve.

\section{Answering Potential Objections}

The preceding analysis shows that there is a correlation between nuclear proliferation and rebel experience among leaders. Yet we still need to be cautious when making claims about this relationship. Our analysis relies on observational data, meaning that rebel experience is not randomly assigned. As we noted throughout the paper, rebels come to power for particular reasons, and those factors - rather than the rebel experience itself - could be driving the relationship we uncovered. We previously accounted for this by controlling for irregular entry, civil wars, and regime type in our statistical models. Here we conduct additional analysis, utilizing what we believe to be the two best statistical techniques available to address this issue. We also conduct other tests to address other possible objections. The relevant findings are displayed in Table 3.

First, we use country fixed effects to model country/unit level factors that may not be captured by our initial empirical analysis. One could argue that it is not advisable to use this technique for our analysis because doing so drops all countries that never pursued the bomb. Our estimation sample therefore declines by 91 percent (from 6,949 to 621 observations) when we employ this method. Yet country fixed effects are useful for addressing the aforementioned criticism: if the alternative interpretation of our findings is correct, the statistical significance of Rebel experience should wash away once we account for previously unmeasured country-level factors. However, as model 5 shows, Rebel experience remains statistically significant at conventional levels $(p<0.001)$ 


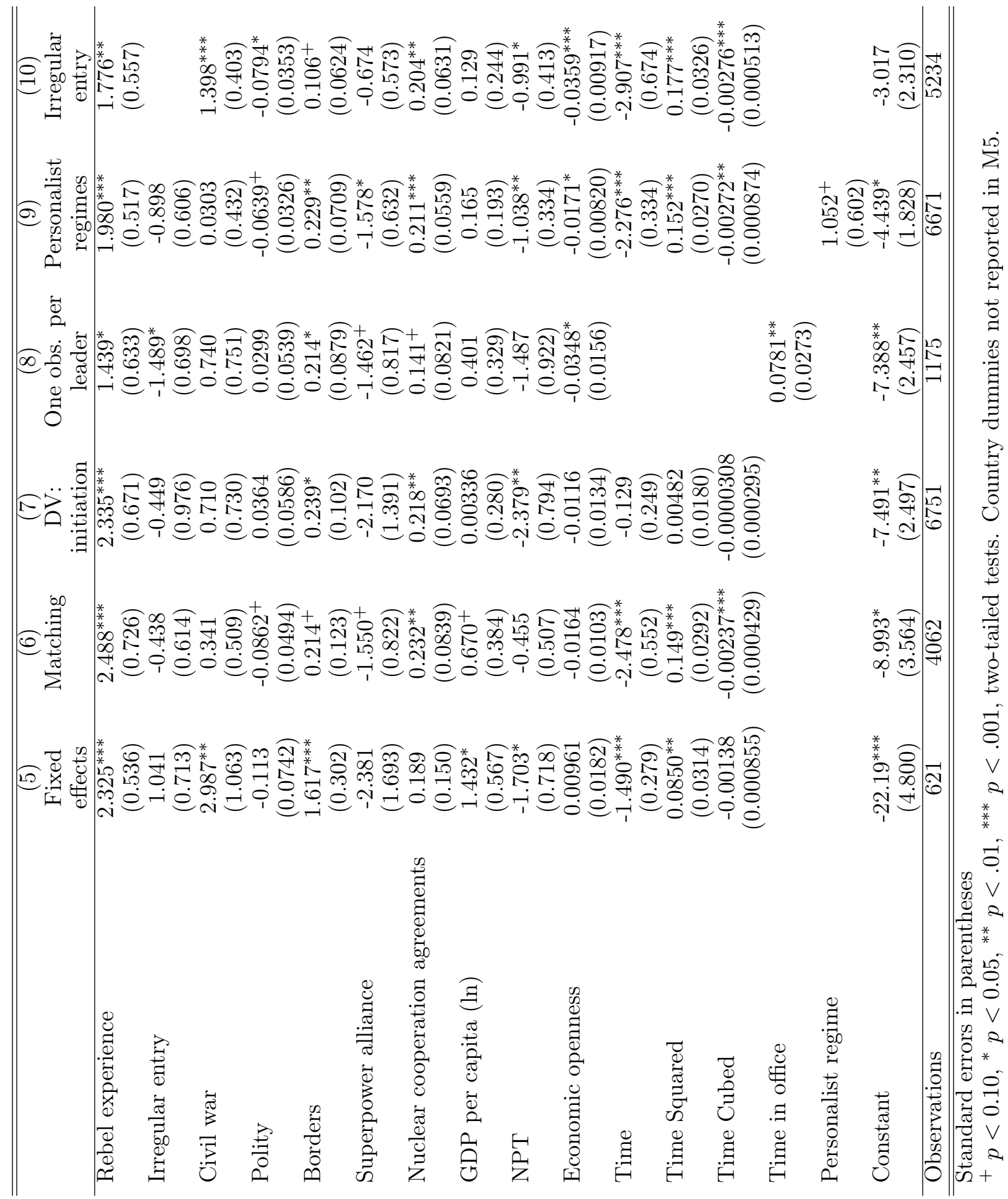


when we employ country fixed effects. The results are also consistent when we use leader random effects with country-clustered standard errors.

Second, we use coarsened exact matching (Iacus et al. 2012) to pre-process the data and improve the balance across the pre-treatment independent variables. ${ }^{24}$ Through this analysis, we can compare observations that are similar when it comes to important pre-treatment control variables but different in terms of rebel experience. In this context, rebel experience is analogous to a "treatment," recognizing, of course, that we cannot perfectly emulate the conditions of a laboratory. We start by identifying the variables on which to match: Irregular entry, Civil war, Polity, borders, and GDP per capita. ${ }^{25}$ Next, we coarsen these variables to create particular categories for each covariate. For instance, we can distinguish among states that have no borders, a moderate number of borders, and a high number of borders. We then create strata that represent all of the possible categories from the coarsened variables (there are 546 such strata), and eliminate strata that do not contain at least one rebel observation and one non-rebel observation. Finally, using the resulting dataset - which is more balanced - we replicate our logit model, weighting observations based on their strata. The results, displayed in model 6, show that Rebel experience remains positive and statistically significant when we estimate our model using a more balanced sample ${ }^{26}$ that was produced using the matching procedure.

We acknowledge here, as we have throughout the paper, that it is difficult to unpack this argument in an observational study. Yet, in our view, the findings from these two analyses strongly suggest that the relationship between rebel experience and nuclear proliferation is, at the very least, not simply a function of how leaders come to power. ${ }^{27}$ Consistent with our theory, rebel experience

\footnotetext{
${ }^{24}$ For other examples that employ a similar procedure see Hopkins (2011); Appel \& Loyle (2012).
}

${ }^{25}$ These variables are causally prior to rebel experience and nuclear proliferation, making them appropriate for our purposes here.

${ }^{26}$ The size of our sample declines by 40 percent (from 6,949 to 4,062 observations) when we employ CEM.

${ }^{27}$ We also re-randomized the distribution of the rebel experience variable and ran 10,000 Monte Carlo draws designed to test the robustness of the relationship between prior rebel experience and nuclear weapons pursuit. The results, available in the online Appendix, show that our rebel experience variable is highly significant even with simulated and re-randomized data. 
itself seems to shape the nuclear proliferation process.

In addition, Table 3 highlights four other robustness tests that directly speak to other concerns about the selection of rebel leaders into office, regime type, the coding of our dependent variable, and the competence of rebels in managing nuclear programs.

Program initiation: The initiation of a nuclear weapons program may be distinct from inheriting a program from a previous leader. We address this concern by testing whether our findings hold when we model the initiation rather than the continuation of nuclear programs. Rebel experience remains statistically significant (model 7), reaffirming that our results are not just an artifact of keeping leaders in the sample after an initial decision to pursue the bomb.

One observation per leader: It is possible that rebel proliferators take longer to build the bomb, perhaps because of technological ineptitude. This could result in a disproportionate number of cases in our sample where rebels pursued nuclear weapons, making it easier to reject the null hypotheses that the relationship between rebel experience and proliferation is indistinguishable from zero. We deal with this concern by estimating a model that only includes one observation per leader. In this analysis, as a more conservative estimation strategy, we cluster the standard errors on the country and include an additional covariate for the length of time a leader spent in office. Rebel experience remains positive and statistically significant (model 8).

Personalist regimes: Way \& Weeks (2012) show that personalist regimes, which are characterized by highly centralized leadership, are more likely to pursue nuclear weapons. Since some former rebels come to power in personalistic regimes, this is another reason that structural and institutional forces unrelated to rebel experience could drive our findings. ${ }^{28}$ However, we continue to find support for our argument when we add a control for personalistic regimes (model 9)..$^{29}$

Irregular entry into office: If our argument is uniquely applicable to rebels, as opposed to those who enter office through irregular means, we would expect the relationship between rebels and proliferation to not only hold when leaders enter office through a coup or revolution, but also

\footnotetext{
${ }^{28}$ As the online appendix shows, the results are also consistent if we add a control for revolutionary leaders or exclude them (Colgan 2010, 674-675).

${ }^{29}$ Limiting the sample to non-personalistic regimes likewise results in a statistically significant relationship between rebel experience and nuclear proliferation.
} 
through "regular" means of succession such as elections (Chiozza \& Goemans 2011). While we already control for this in our main models, consistent with our expectations, we find that Rebel experience remains statistically significant when we limit our sample exclusively to leaders who came to power regularly (model 10). ${ }^{30}$

\section{Additional Robustness Tests}

We conduct further empirical analysis to address a variety of other potential concerns not discussed above or in the footnotes. Due to space constraints, we report the findings discussed here in the online Appendix.

- Alternate nuclear weapons pursuit codings. As discussed previously, some disagreements persist about whether certain countries pursued nuclear weapons or not. To address this issue, we recode our dependent variable using two alternate nuclear proliferation datasets (Way 2011; Jo \& Gartzke 2007). Rebel experience remains closely associated with nuclear weapons pursuit. ${ }^{31}$

- Stable countries excluded. The fact that our main models include regimes that experienced no significant domestic turmoil in a generation could bias the results. To correct for this, we estimate a model that only includes countries that experienced a civil war or had a leader enter office through irregular means during the previous 25 years. Our analysis shows that Rebel experience remains statistically significant.

- Poor countries excluded. One could argue that some states lack the capacity to build nuclear weapons and thus are unlikely to ever pursue the bomb. To evaluate whether including these states biases our results, we excluded leader-year observations representing the poorest states in the world. ${ }^{32}$ Rebel experience remains statistically significant.

\footnotetext{
${ }^{30}$ There is actually a large degree of variation in how former leaders enter office, as mentioned previously and shown in a $2 \times 2$ table available in the online Appendix.

${ }^{31}$ Rebel experience is also significant when we loosen our definition of nuclear weapons pursuit to include those countries that just "explored" nuclear weapons.

${ }^{32}$ We excluded observations when GDP per capita is less than 675 USD - the wealth of the
} 
- France and Yugoslavia excluded. Table 1 suggests that France and Yugoslavia are potentially important countries for our analysis because both states had a series of former rebels who pursued nuclear weapons in quick succession. However, our findings are not dependent on the inclusion of these two countries: the results are similar when we remove these two states from the sample.

- Potentially influential leaders excluded. Our definition of rebel incorporates leaders fighting in units that one could argue resembled regular militaries, as described in the research design section. Yet our findings also hold when we exclude de Gaulle, Ben Gurion, and other potentially influential leaders that might be considered non-rebels.

- Post-NPT period only. Proliferation dynamics may have fundamentally changed following the introduction of the NPT in 1968. Yet Rebel experience remains statistically significant when we limit our analysis to the post-NPT period. This is also true when we control for the Cold War period.

\section{Conclusion}

In this paper, we explore the intersection of two critical areas of interest for international relations scholars: the role of leaders and the proliferation of nuclear weapons. A burgeoning set of international relations research demonstrates that leaders are not just black boxes who pursue policies due to static conceptions of national interest and domestic political constraints. The beliefs of leaders can play a significant role in driving national policy, especially on salient issues. According to most theories of international relations and existing research on nuclear proliferation, however, it does not matter who actually leads a given nation-state when it comes to nuclear proliferation dynamics.

We show, in contrast, that leaders with prior rebel backgrounds are particularly likely to pursue nuclear weapons. Having participated in a struggle for independence against a foreign power or a rebellion against the government, former rebels are particularly likely to seek absolute national security in the form of nuclear weapons. Seeing nuclear weapons as invasion insurance and fearing poorest country ever to initiate a nuclear weapons program: China in 1955. 
the loss of sovereignty, former rebels are much more likely to pursue the bomb than otherwise similarly situated leaders. We show that this result does not just emerge from leaders in autocratic regimes or those that take power after civil wars. Instead, former rebels are significantly more likely to pursue nuclear weapons regardless of regime type. Moreover, the effect of former rebels on the probability of proliferation is larger than many other traditional explanations, including economic capacity and a state's security environment. We therefore offer a novel theory of nuclear proliferation that is robustly supported by the historical record. Our findings underscore the importance of future research on the influence of leaders on proliferation.

One limitation of this study is that it does not reveal precisely why rebel experience raises the risk of nuclear proliferation. We offered two mechanisms - one focusing on national independence and the other on risk - that, in our view, drive the relationship examined in this article. Yet, due to data restrictions, we cannot assess which of these mechanisms is most important. It is also possible that there are other mechanisms that we did not identify. ${ }^{33}$ We leave these issues for future research. Even without knowing exactly why rebel experience raises the risk of proliferation, this article shows that leader backgrounds can usefully predict proliferation. Our study therefore has implications for recent attempts to forecast international political events (Schrodt et al. 2011; Ward et al. 2013).

More generally, this paper demonstrates the viability of continuing research on how the backgrounds of leaders may influence the way nations behave. Leaders can play a prominent role in determining national policy, especially on issues of vital national importance such as the pursuit of nuclear weapons. In addition, prior rebel experience appears related to several quantities of interest for international relations scholars - further research on how prior rebel experience influences the future beliefs of leaders and how this interacts with domestic political institutions is just one likely area for development. Work in this area thus represents a fruitful path for future research with potential applications not only for national security policy, but potentially for international economic policy or even domestic policy issues as well.

${ }^{33}$ These issues are hardly unique to our study. When scholars discover new findings, the exact reasons for an observed relationship are often unclear (e.g., Reiter \& Stam 1998, 388). 


\section{References}

Appel, Benjamin J., \& Loyle, Cyanne E. 2012. The Economic Benefits of Justice: Post-Conflict Justice and Foreign Direct Investment. Journal of Peace Research, 49(5), 685-699.

Aron, Robert. 1966. An Explanation of De Gaulle. New York: Harper and Row.

Beardsley, Kyle, \& Asal, Victor. 2009. Winning with the Bomb. Journal of Conflict Resolution, 53(2), 278-301.

Bleek, Philipp. 2010. Why Do States Proliferate? Quantitative Analysis of the Exploration, Pursuit, and Acquisition of Nuclear Weapons. Pages 159-192 of: Potter, William C, \& Makhatzhanova, Gaukar (eds), Forecasting Nuclear Proliferation in the 21st Century: The Role of Theory. Palo Alto, CA: Stanford University Press.

Bozo, Frederic. 2001. Two Strategies for Europe: De Gaulle, the United States, and the Atlantic Alliance. New York: Rowman and Littlefield.

Carter, David, \& Signorino, Curtis S. 2010. Back to the Future: Modeling Time Dependence in Binary Data. Political Analysis, 18(3), 271-92.

Chiozza, Giacomo, \& Goemans, Hein E. 2011. Leaders and International Conflict. New York: Cambridge University Press.

Cohen, Avner. 1998. Israel and the Bomb. New York: Columbia University Press.

Colgan, Jeff D. 2010. Oil and Revolutionary Governments: Fuel for Conflict. International Organization, 64(4), 661-694.

Colgan, Jeff D. 2013. Domestic Revolutionary Leaders and International Conflict. World Politics, 65(4), 656-690.

Croco, Sarah. 2011. The Decider's Dilemma: Leader Culpability, Domestic Politics, and War Termination. American Political Science Review, 105(3), 457-477.

Dai, Xinyuan. 2002. Information Systems in Treaty Regimes. World Politics, 54(4), 405-436.

Debs, Alexandre, \& Goemans, H.E. 2010. Regime Type, the Fate of Leaders, and War. American Political Science Review, 104(3), 430-445.

Frankel, Benjamin. 1993. The Brooding Shadow: Systemic Incentives and Nuclear Weapons Proliferation. Security Studies, 2(3-4), 37-78. 
Fuhrmann, Matthew. 2012. Atomic Assistance: How 'Atoms for Peace' Programs Cause Nuclear Insecurity. Ithaca, N.Y.: Cornell University Press.

Furniss, Edgar S. 1961. De Gaulle's France and NATO: An Interpretation. International Organization, 15(3), 349-365.

Geddes, Barbara. 2008. Party Creation as an Autocratic Survival Strategy. Typescript, UCLA.

Gellman, Barton, \& Walsh, Edward. 1998. President Narrows Goals for Airstrikes. Washington Post.

Gleditsch, Nils Petter, Wallensteen, Peter, Eriksson, Mikael, Sollenberg, Margareta, \& Strand, Havard. 2002. Armed Conflict 1946-2001: A New Dataset. Journal of Peace Research, 39(5), $615-637$.

Goemans, Hein E., Gleditsch, Kristian, \& Chiozza, Giacomo. 2009. Introducing Archigos: A Dataset of Political Leaders. Journal of Peace Research, 46(2), 269-283.

Goldgeier, James M. 1994. Leadership Style and Soviet Foreign Policy: Stalin, Khrushchev, Brezhnev, Gorbachev. Baltimore: The Johns Hopkins University Press.

Goldstein, Avery. 2005. Rising to the Challenge: China's Grand Strategy and International Security. Palo Alto, CA: Stanford University Press.

Grosser, Alfred. 1963. General De Gaulle and the Foreign Policy of the Fifth Republic. International Affairs, 39(2), 198-213.

Hopkins, Daniel J. 2011. Translating Into Votes: The Electoral Impacts of Spanish Language Ballots. American Journal of Political Science, 55(4), 814-830.

Hymans, Jacques. 2006. The Psychology of Nuclear Proliferation: Emotions, Identity, and Foreign Policy. New York: Cambridge University Press.

Iacus, Stefano M., King, Gary, \& Porro, Giuseppe. 2012. Causal Inference without Balance Checking: Coarsened Exact Matching. Political Analysis, 20(1), 1-24.

Jervis, Robert. 1976. Perception and Misperception in International Politics. Princeton: Princeton University Press.

Jo, Dong-Joon, \& Gartzke, Erik. 2007. Determinants of Nuclear Weapons Proliferation. Journal of Conflict Resolution, 51(1), 167-94.

Kalyvas, Stathis, \& Kocher, Matthew. 2007. How Free is "Free Riding" in Civil Wars? World 
Politics, 59(2), 177-216.

Kennedy, Andrew B. 2011. The International Ambitions of Mao and Nehru: National Efficacy Beliefs and the Making of Foreign Policy. New York: Cambridge University Press.

King, Gary, \& Zeng, Langche. 2006. The Dangers of Extreme Counterfactuals. Political Analysis, 14, 131-159.

Krepon, Michael. 2009. Better Safe Than Sorry: The Ironies of Living with the Bomb. Palo Alto, CA: Stanford University Press.

Lewis, John Wilson, \& Litai, Xue. 1988. China Builds the Bomb. Palo Alto, CA: Stanford University Press.

Marshall, Monty G., Gurr, Ted Robert, \& Jaggers, Keith. 2009. Polity IV Project: Political Regime Characteristics and Transitions, 1800-2009.

Matthews, David R. 1954. The Social Background of Political Decision-Makers. New York: Random House.

Narang, Vipin. 2009. Posturing for Peace: Pakistan's Nuclear Postures and South Asian Stability. International Security, 34(3), 38-78.

O’Reilly, K.P. 2012. Leaders' Perceptions and Nuclear Proliferation: A Political Psychology Approach to Proliferation. Political Psychology, forthcoming.

Park, Chung Hee. 1970. Country, the Revolution, and I. Seoul: Hollym Corp.

Paul, T.V. 2000. Power versus Prudence: Why Nations Forgo Nuclear Weapons. Montreal: McGillQueens University Press.

Perkovich, George. 1999. India's Nuclear Bomb: The Impact on Global Proliferation. Berkeley: University of California Press.

Reiter, Dan. 2006. Preventive Attacks against Nuclear, Biological, and Chemical Weapons Programs: The Track Record. In: Keller, William W., \& Mitchell, Gordon R. (eds), Hitting First: Preventive Force in US Security Strategy. Pittsburgh: Pittsburgh University Press.

Reiter, Dan, \& Stam, Allan C. 1998. Democracy, War Initiation, and Victory. American Political Science Review, 92(2), 377-389.

Rhodes, Richard. 1986. The Making of the Atomic Bomb. New York: Simon and Schuster. Rice, Edward. 1972. Mao's Way. Berkeley, CA: University of California Press. 
Roberts, Brent W., Gaspi, Avshalmon, \& Moffitt, Terrie E. 2003. Work Experiences and Personality Development in Young Adulthood. Journal of Personality and Social Psychology, 84(3), 582-593. Rublee, Maria Rost. 2009. Nonproliferation Norms: Why StateChoose Nuclear Restraint. Athens, GA: University of Georgia Press.

Sagan, Scott D. 1996. Why Do States Build Nuclear Weapons?: Three Models in Search of a Bomb. International Security, 21(3), 54-86.

Saunders, Elizabeth N. 2011. Leaders at War: How Presidents Shape Military Interventions. Ithaca, NY: Cornell University Press.

Schrodt, Philip A., Brandt, Patrick T., \& Freeman, John R. 2011. Real Time, Time Series Forecasting of Inter- and Intra-State Political Conflict. Conflict Management and Peace Science, 28(1), $41-64$.

Schwartz, Benjamin I. 1951. Chinese Communism and the Rise of Mao. Cambridge, MA: Harvard University Press.

Sechser, Todd S. 2004. Are Soldiers Less War-Prone Than Statesmen? Journal of Conflict Resolution, 48(5), 746-774.

Singh, Sonali, \& Way, Christopher R. 2004. The Correlates of Nuclear Proliferation: A Quantitative Test. Journal of Conflict Resolution, 48(6), 859-85.

Solingen, Etel. 2007. Nuclear Logics: Contrasting Paths in East Asia and the Middle East. Princeton, NJ: Princeton University Press.

Spirtas, Michael. 1998. French Twist: French and British NATO Policies from 1949 to 1966. Security Studies, 8(2-3), 302-346.

Svolik, Milan. 2007. Power-Sharing and Leadership Dynamics in Authoritarian Regimes. American Journal of Political Science, 53(2), 477-494.

Thompson, Robert S. 1974. Pledge to Destiny: Charles de Gaulle and the Rise of the Free French. New York: McGraw-Hill.

Waltz, Kenneth N. 1990. Nuclear Myths and Political Realities. American Political Science Review, 84(3), $731-45$.

Ward, Michael D., Metternich, Nils W., Dorff, Cassy, Gallop, Max, Hollenbach, Florian M., Schultz, Anna, \& Weschle, Simon. 2013. Learning from the Past and Stepping Into the Future: Toward 
a New Generation of Conflict Prediction. International Studies Review, 15(4).

Way, Christopher R. 2011. Nuclear Proliferation Dates. Typescript, Cornell University.

Way, Christopher R., \& Weeks, Jessica L. 2012. Making it Personal: Regime Type and Nuclear Proliferation. Typescript, Cornell Unviersity. 